\title{
ESTUDO PRELIMINAR DA VARIAÇÃO DE MICRO-FORMAS E DA COBERTURA VEGETAL NA GERAÇÃO DO RUNOFF E PERDA DE SOLO EM VERTENTE DO MUNICÍPIO DE GOUVEIA/MG
}

\author{
Valéria. C.C. Barbosa ${ }^{1} \&$ Cristina H.R.R. Augustin ${ }^{2}$
}

\begin{abstract}
This study intents to analyze with the mechanical work of the rain runoff in the region of Gouveia - Espinhaço Meridional, State of Minas Gerais, Brazil, under natural conditions and not induced rainfall. It shows significant differences in the denudation processes taking place on the ground surface, due to the variation of micro-forms and the vegetation cover.

The hydro-erosive date for the period between February and September/00 indicate a more accelerated lowering of the ground surface on the lower slope. In the areas with lower vegetation cover, the runoff flow cuts down the soil surface, deepening the micro-ravines. In other places of the slope where the hydrological forces are week and vegetation cover thicker, a higher stability of the micro- topography and a more moderate deposition of the sediments can be observed.

Key words: Micro-forms; vegetation cover; runoff; soil erosion.
\end{abstract}

\section{INTRODUÇÃO}

As irregularidades da superfície do solo com dimensões de ordem menores que a seqüência da vertente são denominadas micro-topografias (YOUNG, 1972). As micro-elevações da vertente correspondem em geral à superfície pedregosa, a termiteiro/ formigueiro, a tufos de grama ou à área de raiz da planta, onde os sedimentos são acumulados. As microdepressões, por sua vez, correspondem à trilha do gado e a áreas onde o solo está sendo mobilizado. Tais feições são freqüentes em solos pouco desenvolvidos, mas também naqueles degradados pelo uso agropecuário (YOUNG op cit., SOLE-BENET et al, 1997).

Entre os vários fatores controladores dos processos hidro-erosivos de vertente, a cobertura do solo e as micro-topografias são consideradas as de maior expressão tempo-espacial em áreas com pequenas dimensões. Nessas porções da vertente os fatores climáticos e a litologia são praticamente homogêneos, condicionando os processos geomorfológicos às pequenas mudanças da morfologia da superfície (BRYAN et al., 1978 in SOLE-BENET et al 1997) e da cobertura de solo (WILDNER, 1985).

A vegetação é também de grande importância nos estudos de erosão, uma vez que ela controla a natureza, quantidade e velocidade da atuação dos processes geomorfológicos. Da mesma maneira, a estrutura e a composição da vegetação sofre grande influência dos processos geomorfológicos, através da remobilização e transporte do solo e de nutrientes, além da alteração de teores de umidade e temperatura decorrentes das novas formas produzidas pela ação desses processos (THORNES, 1990).

A interação entre os fatores erosivos pode, na prática, inverter a tendência normal de maior geração de sedimentos durante chuvas mais intensas, podendo ocorrer taxas de erosão mais elevadas sob chuvas menos intensas (RESENDE; CARVALHO FILHO E LANI, 1990) ou em áreas de maior densidade vegetal.

Avaliações preliminares do trabalho mecânico da água de superfície sob condições de chuva natural na área de estudo têm revelado diferentes comportamentos hidro-erosivos ao longo da vertente (AUGUSTIN; BARBOSA \& MARCHIORO 2000) corroborando as considerações acima apresentadas.

Objetivou-se nesta pesquisa determinar o volume de solo perdido por erosão superficial dispersa, utilizandose medidas da variação da micro-topografia, bem como analisar a importância da cobertura de solo (vegetacional ou não) e da micro-forma no comportamento hidrológico em estações experimentais na região de Gouveia, Espinhaço Meridional, MG, Brasil.

\footnotetext{
ÁREA DE ESTUDO

A área localiza-se no município de Gouveia, a 260 km de Belo Horizonte (Fig.1). No município, a amostragem foi realizada na Depressão de Gouveia, depressão esculpida sobre os quartzitos do Supergrupo Espinhaço, expondo os xistos, migmatitos e granitos do embasamento cristalino.
} 


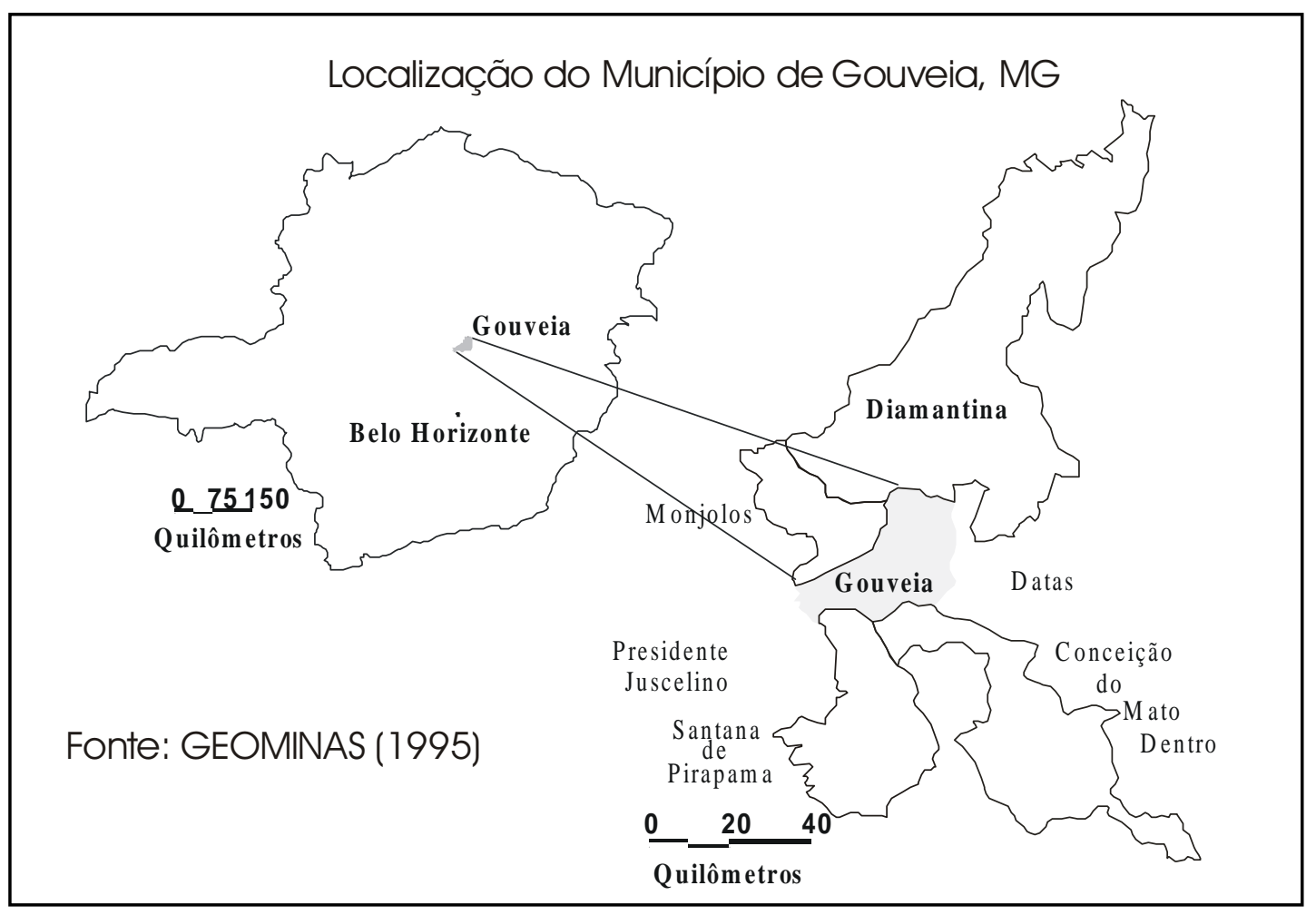

Figura 1: Localização da área de estudo.

Figure 1: Location map.

AUGUSTIN (1995), identificou na área, cinco grandes unidades morfoestruturais. A primeira se encontra acima de $1300 \mathrm{~m}$, elaborada nos quartzitos da Formação São João da Chapada. A segunda ocorre entre 1.200-1300m, sobre os ortoquartzitos da formação Galho do Miguel. A terceira, entre $1.100 \mathrm{~m}$ e $1.200 \mathrm{~m}$, foi elaborada principalmente sobre os xistos do Grupo Costa e Sena, que foi denominada pela autora como "Superfície Residual Antiga". A quarta entre 1100 e $1000 \mathrm{~m}$ foi elaborada principalmente sobre os xistos do Supergrupo Rio Paraúna, algumas vezes muito milonitizados. Abaixo dos $1.000 \mathrm{~m}$, predomina o granito-gnaisse, milonitizado ou não, pertencente ao embasamento cristalino.

O clima da área de estudo, segundo a classificação de Köppen, é do tipo Cwb - Mesotérmico, com verões brandos e úmidos, e invernos secos e de baixas temperaturas. $\mathrm{O}$ período seco ocorre entre os meses de maio a setembro e o chuvoso de outubro a abril. A precipitação média anual, calculada no período de 1941 a 1999, segundo dados da Agência Nacional de Energia Elétrica- (ANEL) é de $1.336 \mathrm{~mm}$, concentradas principalmente entre os meses de dezembro e fevereiro; o período mais seco ocorre entre junho e agosto. A região está inserida no Domínio do Cerrados, que apresenta variações locais em função das características do clima, solo e geologia. A ocupação, relativamente antiga da área, remontando ao período colonial, constitui fator importante nas características que o cerrado apresenta. Trata-se de uma cobertura degradada, com predomínio do estrato gramíneo-herbáceo, árvores baixas (médias de $2 \mathrm{~m}$ da altura) e dispersas. Esta cobertura é submetida anualmente, durante os meses de agosto e setembro, à queimadas (ORTIZ, 2000)

Os solos mais comuns são os Latossolos Vermelho Amarelos e Vermelho Escuros, bem desenvolvidos e pobres em nutrientes. Também estão presentes na área o Cambissolo, as Areias Quartzosas e o solo Gley, este último ao longo dos cursos de água ou nas baixadas (ÁDAMO, 2001).

\section{PROCEDIMENTOS METODOLÓGICOS}

Os dados foram coletados em três estações experimentais (parcelas), de $100 \mathrm{~m}^{2}$ cada, instaladas em sítios Geomorfológicos identificados a partir de rupturas de declive no perfil da vertente, como apresentado abaixo:

Foram instaladas três parcelas localizadas na alta (P1), média (P2) e baixa vertente (P3), na bacia do córrego Gameleira, afluente do Cuibá, pertencente à bacia do ribeirão do Chiqueiro, a segunda mais importante do município. A micro-forma e a cobertura de solo foi amostrada ao longo dos 15 transectos de 10 m cada (6 na direção do escoamento e 9 horizontais) subdivididos em segmentos de $25 \mathrm{~cm}$.

A amostragem da vegetação fundamentou-se nas considerações metodológicas dos trabalhos DE MULLER-DOMBOIS \& ELLENBERG (1974), MATTEUCCI \& COLUNA (1982) e GOUDIE, (1981). 


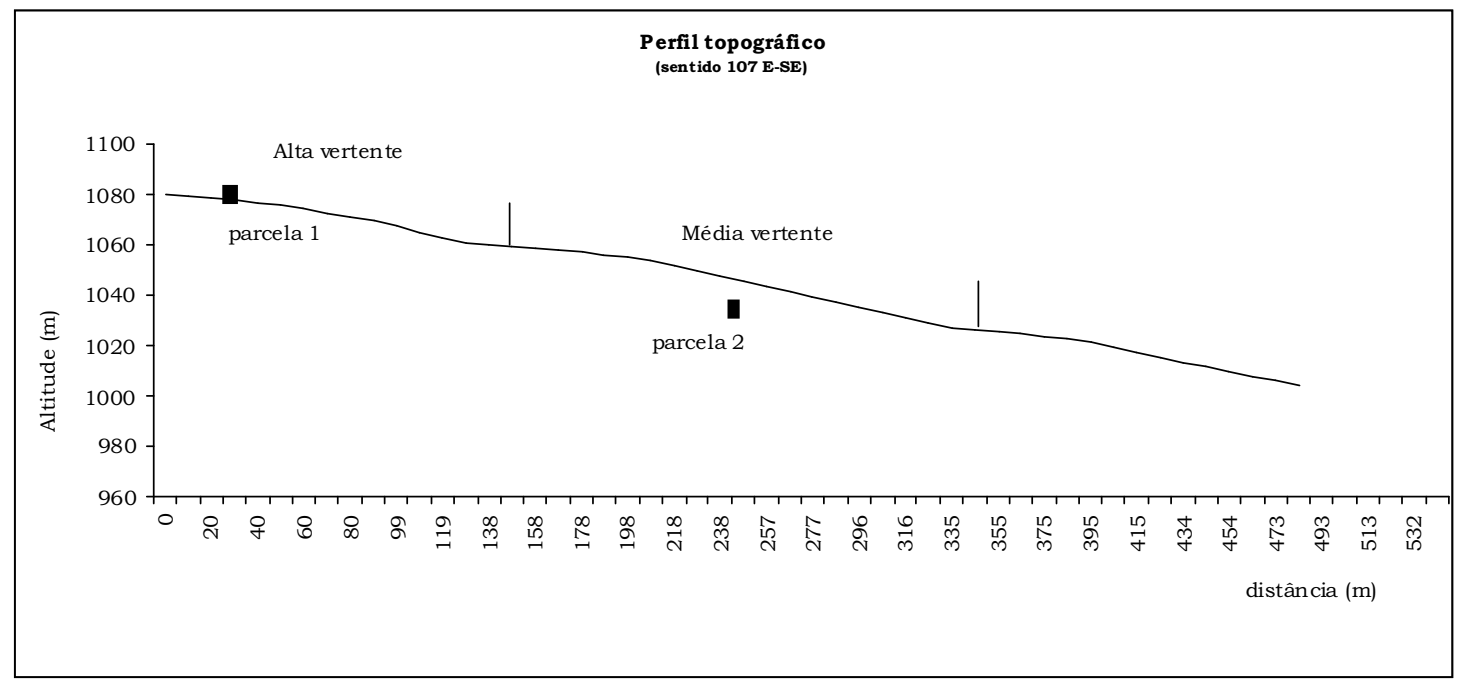

Figura 2: Localização das parcelas nos sítios Geomorfológicos.

Figure 2: Localization of the geomorphologic parcels.

A densidade de cobertura vegetal foi obtida através do método do transecto (Line transect) bastantes utilizado em trabalhos de Geomorfologia. Essa técnica consiste no registro da porção da vegetação que intercepta uma linha reta (transecto) estendida acima da cobertura vegetal. Desta forma, a projeção horizontal da vegetação (abertura de copa) sobre a superfície, ao longo da linha do transecto, é registada utilizando uma trena. A área recoberta pela vegetação foi estimada para cada parcela, utilizando-se a seguinte fórmula:

$$
A c v=\frac{\sum C V}{\sum \text { Transectos }} \times P
$$

Acv: Área de Cobertura vegetal $\left(\mathrm{m}^{2}\right)$

$C V_{t}$ : Cobertura vegetal total (m)

$P$ : Comprimento da parcela $(10 \mathrm{~m})$

O levantamento da cobertura de superfície, entendida aqui como todos os materiais encontrados sobre o solo desnudo de cobertura vegetal, foi feito em fevereiro em cada seguimento. Foram identificados o tipo e calculada a percentagem de recobrimento e após calculou-se o percentual para toda a área amostrada da parcela.

Para a amostragem da micro-topografia foram instalados transectos de fío de aço $(0,30 \mathrm{~mm}$ de diâmetro) estendidos a $95 \mathrm{~cm}$ de altura do chão, acima daqueles usados para a vegetação.

A micro-topografia foi calculada medindo-se a altura entre o fio de aço e o solo, sendo que os valores acima de $95 \mathrm{~cm}$ (superfície regular) foram considerados micro-depressão e os abaixo: micro-elevação. Tais valores foram obtidos em distância regulares de $25 \mathrm{~cm}$.

$\mathrm{O}$ volume de solo erodido é calculado pela média do volume da superfície em um primeiro momento (t1) em relação a outro (t2). A estimativa foi determinada pela fórmula:

$$
\begin{aligned}
& \mathrm{MV}_{\mathrm{s}}=\underset{\left.\sum_{\mathrm{t}}-\mathrm{H}_{\mathrm{MF}}\right) \times \mathrm{T} \times \mathrm{P}}{\sum \text { ponto de amostragem }} \rightarrow \mathrm{V}_{\mathrm{tE}=} \mathrm{MV}_{\mathrm{s} 1}-\mathrm{MV}_{\mathrm{s} 2} \\
& \mathrm{MV}_{\mathrm{s}}=\text { Média do volume da superfície }\left(\mathrm{m}^{3}\right) \\
& \mathrm{V}_{\mathrm{tE}=} \text { Volume total Erodido }\left(\mathrm{m}^{3}\right) \\
& \mathrm{D}_{\mathrm{TS}}=\text { Distância inicial do }(0,95 \mathrm{~m}) \text { transecto ao solo } \\
& \mathrm{H}_{\mathrm{MF}=} \text { Altura da Micro-Forma ao transecto }(\mathrm{m}) \\
& \mathrm{T}=\text { Comprimento da Parcela }(10 \mathrm{~m}) \\
& \mathrm{P}=\text { Largura da Parcela }(10 \mathrm{~m})
\end{aligned}
$$

\section{RESULTADOS}

Os resultados, após as medidas do t1 e t2, demonstram que os eventos chuvosos atuam de maneira diferenciada no espaço, refletindo as variações locais de precipitação, interceptação e redistribuição da água da chuva em cada porção da vertente.

Há evidências de que as características da microforma da vertente, juntamente com a cobertura de solo (vegetal e não vegetal), são responsáveis por tais variações locais, demonstrando a complexa relação entre infiltração e escoamento, erosão e vegetação.

A primeira parcela foi instalada em um seguimento levemente convexo, a segunda em outro levemente côncavo, correspondendo a área de transição para a baixa vertente, e o terceiro sítio localiza-se em um elemento retilíneo da vertente.

Os dados relativos às características gerais das parcelas (Figura 1) mostram a predominância de um solo pedregoso, relativamente recente, classificado como cambissolo. A pedregosdade é proveniente de um veio de quartzo que ora aparece em profundidade, como nos solo localizados no topo da vertente onde a força 


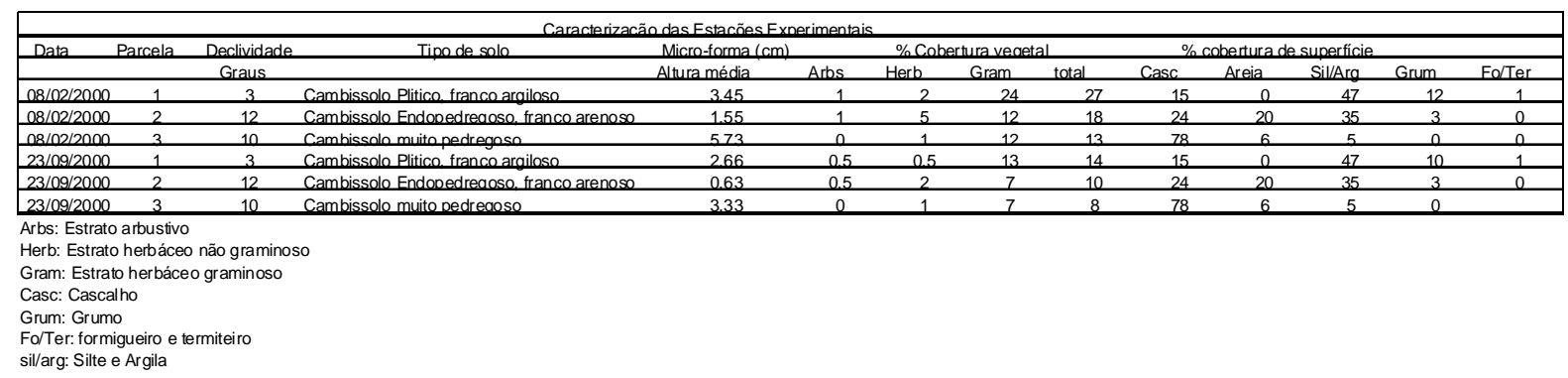

Figura 3: Tabela de Caracterização das Estações Experimentais.

Figure 3: Table with the caracterization of the experimental stations.

hidráulica é fraca e a erosão não carreou o material de alteração que ocorre acima do veio, ora em superfície, como na média e baixa vertentes, devido ao aumento da competência do escoamento superficial e a proximidade da zona de instabilidade, entre a vertente e o terraço fluvial.

As resultantes hidro-erosivas (perda de solo e microforma) tiveram uma significativa variação na área das parcelas, no período de fevereiro/00 à setembro/00 (Graf.2). Algumas características comuns a todas as parcelas foram constatadas:

(a) rebaixamento da superfície do solo no período de menor cobertura vegetal, ou seja, no final do período seco e início do período chuvoso (setembro);

(b) aprofundamento das micro-ravinas nos seguimentos onde a vegetação é ausente ou escassa;

(c) relativa estabilidade das micro-formas da vertente e moderada acumulação dos sedimentos transportados em locais onde a força hidráulica é fraca. Nestas áreas, predomina o material granular argilosiltoso, formando um tapete que recobre o solo, e a vegetal mais densa.

\section{Análise da variação da micro-forma nas estações experimentais}

A grande variabilidade da micro-topografia é decorrente do efeito associado entre os fatores vegetação, cobertura de solo e escoamento superficial.

A análise das micro-formas nas três parcelas, indica a maior variabilidade da segunda, localizada na meia vertente no período de fevereiro à setembro (Figura $3 \mathrm{e}$ 4). Em função disto se apresentará somente os resultados obtidos nessa parcela, para a análise das micro-formas.

A partir dos perfis do micro-relevo (figura 3), notase a formação de duas compartimentações bem definidas pela anisotropia da cobertura do solo e morfologia da superfície. A primeira compartimentação, correspondente aos primeiros $400 \mathrm{~cm}$ do início do transecto, caracterizada pelo material superficial representado predominantemente por seixo e areia (74\%) e baixo percentual de cobertura vegetal $(9 \%)$. $\mathrm{Na}$ segunda, prepondera o material argilo-siltoso granular $(61 \%)$ e uma cobertura vegetal mais densa (15\%).

A análise dos resultados do primeiro transecto horizontal situado próximo ao topo da parcela $\mathbf{T 1 H}$ (Figura 3), mostra a formação de micro-depressão (0 à $475 \mathrm{~cm}$ ) indicando que erosão do solo foi bastante ativa. $\mathrm{O}$ fato da cobertura vegetal ser escassa ou mesmo nula em torno da micro-depressão parece contabilizar primordialmente para a perda de solo neste compartimento. Contudo, a grande pedregosidade, representada por seixos, com diâmetros médios de 4 $\mathrm{cm}$, pode substituir a vegetação no papel de interceptador das gotas de chuva, reduzindo seu impacto direto sobre a superfície do solo e facilitando a infiltração. Sobre a cobertura granular argilo-arenosa e vegetação densa e contínua, os sedimentos encontramse confinados em torno das raízes das plantas. Elas funcionam como diques de contenção de sedimentos que conformam a micro-elevação. A ocorrência de textura grosseira, formada por solo silto-arenoso, com predomínio de areia fina, no entanto, pode está contribuindo para a aumentar a macroporosidade do solo e o tempo de geração do runnof. As maiores elevações medidas, no entanto, correspondem ao termiteiros.

A figura 3, do segundo transecto horizontal, situado no meio da parcela $\mathbf{T 2 H}$, mostra que o primeiro compartimento é marcado pela presença de duas microelevações. A comparação das microformas desse compartimento com aquela mostrada no perfil acima descrito (T1H), revela que a micro-forma original teve sua morfologia invertida de depressão para elevação. Tal fato sugere ter havido um desvio do escoamento superficial pela vegetação que se interpôs à direção do fluxo. Outra evidência desse fato pode ser verificada no segundo compartimento, através do escavamento de uma micro-depressão pela água desviada pela vegetação, constituindo possivelmente um prolongamento da concavidade identificada no perfil acima. A vegetação herbácea não graminosa parece exercer pouca influência no processo de formação da micro-depressão. Quase a metade da cobertura vegetal amostrada nesse compartimento (0 à $400 \mathrm{~cm}$ ) é constituída por este estrato, cuja folhagem desaparece no período de stress hídrico.

Há indícios de que o fluxo preferencial tenha se iniciado na ocasião das primeiras chuvas, quando o estrato herbáceo era pouco significativo (2\%). Mesmo 
com o crescimento restabelecido da folhagem das herbáceas no final do período chuvoso (fevereiro), a maior parte das espécies desse estrato não possui uma ampla e eficiente área foliar (5\%)para servir de proteção ao solo.

Quanto à cobertura de superfície, a maior presença de material granular silto-argiloso e areia fina $(51 \%)$ em comparação com a dos seixos, pode ter contribuído para aumentar do poder erosivo do fluxo, devido à baixa coesão das partículas de areia que são mais facilmente transportáveis.
O terceiro compartimento tem um perfil microtopográfico semelhante ao do T1H, embora a elevação se apresente menos representativa.

No terceiro transecto horizontal, situado próximo a calha (T3H), o prolongamento da micro-depressão no compartimento de 0 a $400 \mathrm{~cm}$, indica a formação do caminho preferencial da drenagem. O rebaixamento da superfície nesse primeiro compartimento pode ser resultado da interferência de vários fatores: a diminuição da cobertura vegetal, na mesma medida que aumenta o teor de areia fina (facilitando a desagregação do solo) e aumenta a energia do fluxo de superfície.
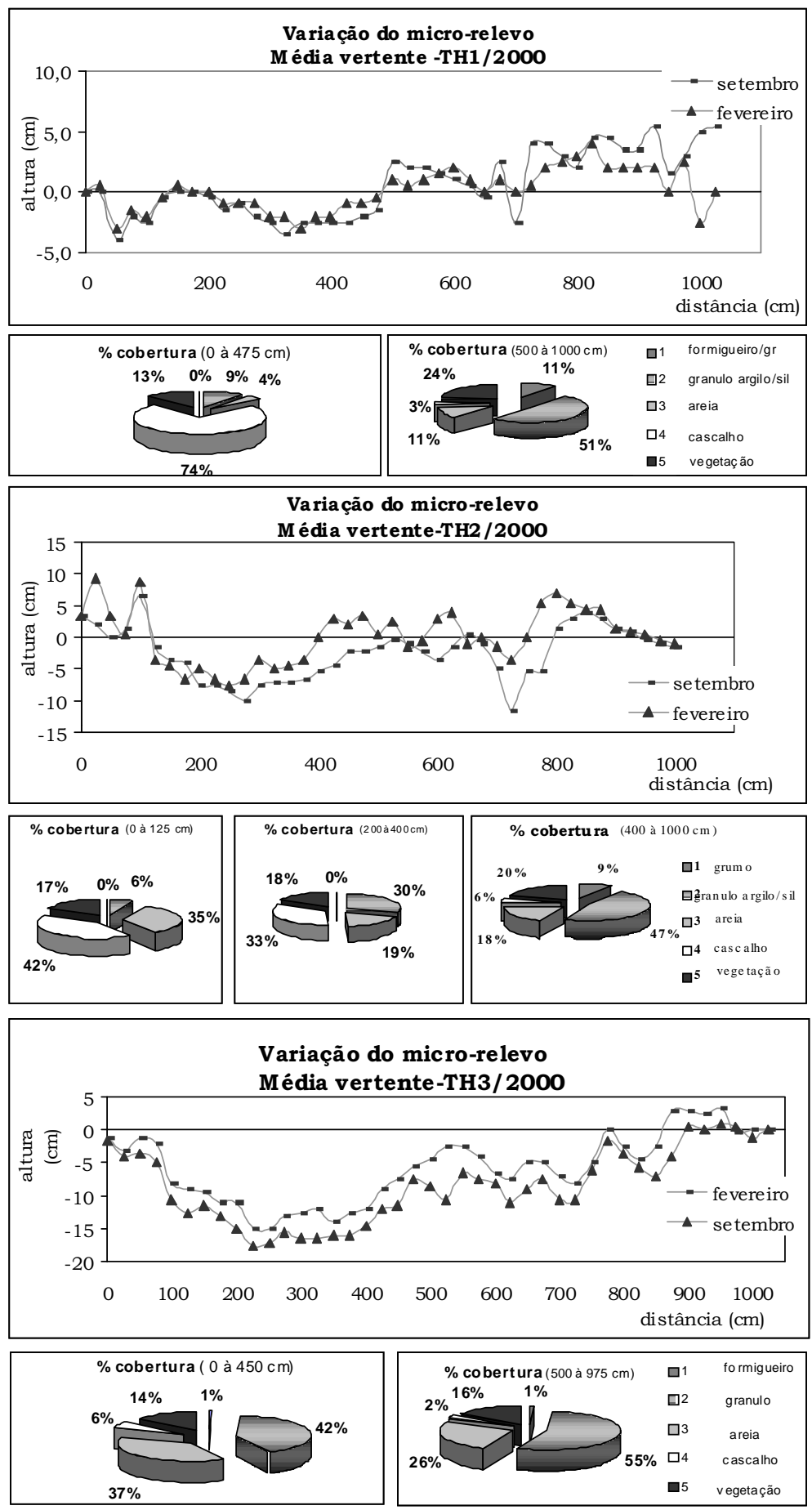

Figura 4: Variação do Micro-relevo da Média Vertente.

Figure 4: Variation of micro-relief into the medium slope. 
A influência dos fatores micro-relevo, cobertura vegetal e cobertura de solo no processo de erosão laminar

As primeiras chuvas de verão (setembro) mostraram uma significativa competência para gerar runnof e remodelar a superfície do solo. Os perfis do micro-relevo indicam um rebaixamento diferenciado da superfície de fevereiro em relação à de setembro, em todas as parcelas (Figura 4).

O menor valor de perda de solo ocorreu no topo $\left(0,79 \mathrm{~m}^{3}\right)$, onde a cobertura vegetal é mais densa e teoricamente a força hidráulica é mais baixa, confirmando as considerações da maioria dos estudiosos (MORGAN, 1980; 1997; STOCKING, 1985; QUEIROZ NETO, 1989 entre outros). Contudo, em estudos preliminares, verificou-se que a vegetação introduzida nessa porção da vertente (capim) exerce uma função ambígua sobre a resultante hidro-erosiva. Se por um lado a maior área foliar, garante maior interceptação das gotas da chuva, por outro ela pode intensificar o processo erosivo através da formação de canaletas ou "rill erosion" (COELHO NETTO, 1992). Isto acontece porque a água acumulada na folhagem é convergida pelo sistema de folhas do vegetal até a base do tufo ("stem flow"), onde o solo geralmente encontra-se saturado, levando ao escoamento.

Em setembro, quando a vegetação é menos densa, grande parte do solo fica vulnerável à erosão. O material de superfície composto por partículas finas é desagregado e compactado formando uma capa síltica.

A parcela da média vertente, apesar de estar sob o maior gradiente, não teve a maior taxa de erosão, o volume de erosão foi aproximada ao obtido no topo $\left(0,91 \mathrm{~m}^{3}\right)$, o que sugere um controle mais efetivo da vegetação sobre a declividade.

A comunidade vegetal da média vertente, do ponto de vista fisionômico e de sua distribuição na parcela, garante maior proteção ao solo do que a vegetação encontrada no topo, uma vez que a vegetação natural da segunda parcela é mais estratificada e cresce espalhando-se pela superfície. Outro fator que que está associado à minimização do efeito da declividade média de $12^{0}$ da vertente é a cobertura de seixos. Nas porções onde não há vegetação, a superfície rugosa reduz os efeitos do trabalho mecânico da água de superfície.

$\mathrm{Na}$ estação experimental da baixa vertente foi registrado o maior valor de perda de solo $\left(2,45 \mathrm{~m}^{3}\right)$, decorrente, principalmente, da intensificação do fluxo nessa porção da encosta. A concentração dos seixos na superfície denota que houve a ação de uma lavagem mais intensa das partículas finas. O escoamento mostrase altamente erosivo mesmo ocorrendo sob superfície rugosa. A intensificação do fluxo de superfície e a pouca cobertura vegetal associados à proximidade de uma zona de instabilidade da encosta (terraço fluvial) respondem pelo rebaixamento mais acelerado da superfície da baixa vertente (Figura 4).
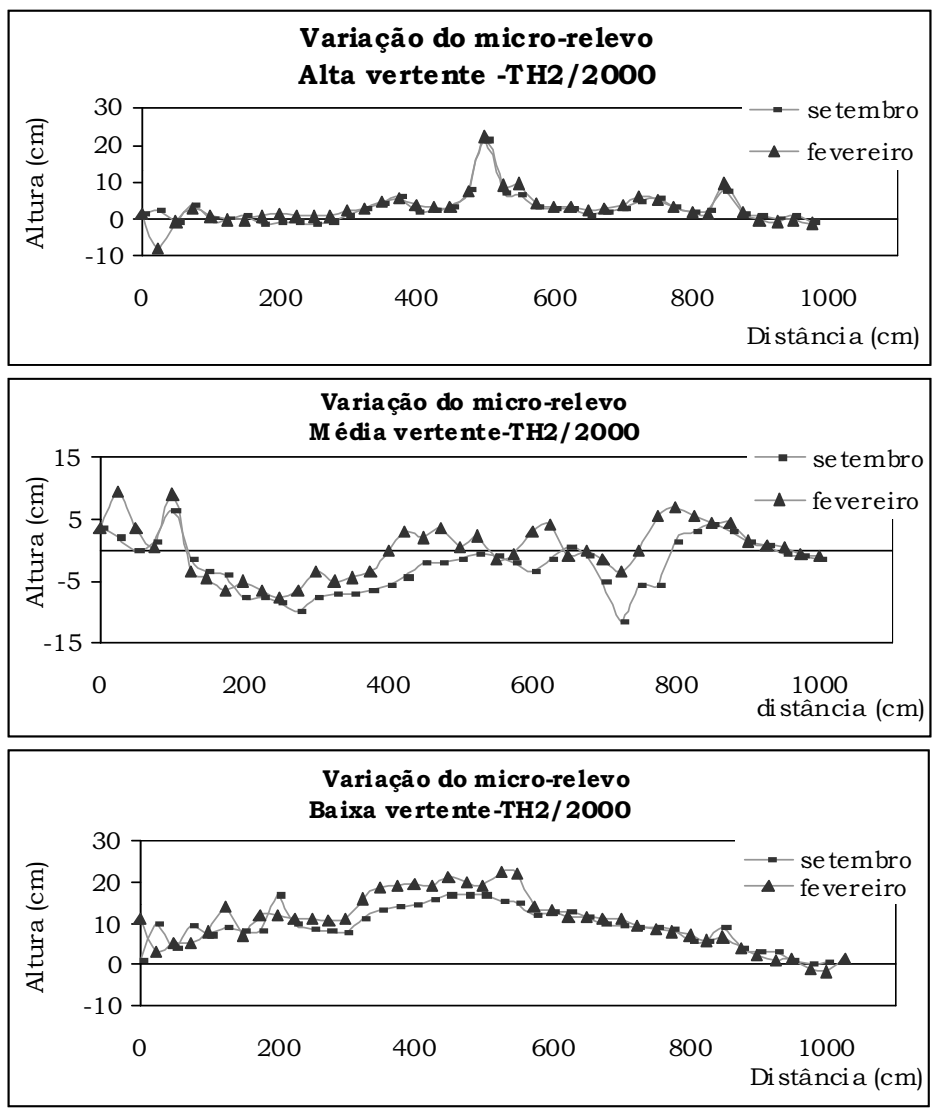

Figura 5: Variação do micro-relevo nas três parcelas estudadas.

Figure 5: Variation of micro-relief in the three studied parcels. 


\section{CONSIDERAÇÕES FINAIS}

A relação entre erosão e vegetação é, segundo Thornes (1985), competitiva. Esta afirmativa pode ser constatada na área de estudo, onde os dados da perda erosiva e da cobertura vegetal coleta mostram variações representativas, apontando para a importância dessa relação. Os dados analisados mostram que em setembro, no final do período seco, quando a vegetação apresentava menor densidade de folhas, a erosão atingiu seus maiores índices, enquanto em fevereiro, quase final do período úmido, quando ocorre o máximo crescimento das folhagens, a vegetação tende a minimizar os efeitos dos processos erosivos. Os resultados indicam, ainda, que a correlação entre erosão e cobertura de solo não é linear, sendo necessário considerar fatores qualitativos, como por exemplo, os aspectos fisionômico estrutural, no caso da vegetação e da cobertura de superfície e a compactação dos finos da camada superficial, bem como a distribuição da cobertura de solo na parcela e sua associação com outros fatores.

As resultantes hidro-erosivas denunciam um ritmo de desnudação acelerado em toda a encosta com as primeiras chuvas de verão. $\mathrm{O}$ efeito do escoamento superficial difuso mostrou-se diferenciado nas parcelas sobre uma mesma cobertura de solo e declividade, indicando que a variação da micro-forma da vertente (deposição e erosão) parece estar condicionada à mudanças da vegetação ao longo do período chuvoso, entre outros fatores.

Algumas formas erosivas detectadas nesse estudo preliminar, como a formação da micro-ravina, podem ser utilizadas como indicadoras do processo de evolução da vertente.

\section{AGRADECIMENTOS}

À FAPEMIG (CRA:1669/95), à FINEP, pelo financiamento da pesquisa e ao CNPq, pela bolsa de Iniciação Científica

\section{REFERÊNCIA BIBLIOGRÁFICA}

ÁDAMO, R. \& AUGUSTIN, C.H.R.R. 2001. Caracterização hidrológica da zona não-saturada do solo em 3 vertentes localizadas na bacia do ribeirão do Chiqueiro, Gouveia, MG, serra do Espinhaço meridional. Instituto de Geociência. Belo Horizonte: UFMG, 2001. 152p.(Dissertação de Mestrado).

AUGUSTIN, C.H.R.R. 1985. A Geografia Física: O levantamento Integrado e Avaliação de Recursos Naturais. Boletim de Geografia Teorética, 15:141-153-.

AUGUSTIN, C.H.R.R. 1995. Aspectos Geomorfológicos da Região de Gouveia, Espinhaço Meridional, MG. IN Anais do $8^{0}$ Simpósio de Geologia de Minas Gerais, 13: 3-4,.

COELHO NETTO, A. L. 1992. O Geoecossistema da Floresta da Tijuca in Natureza e Sociedade no Rio de Janeiro, organizado por ABREU, M. A.; coleção biblioteca carioca, 21:104-142.

GOUDIE, A. 1981. Geomorphological Techiniques. British Geomorphological Research Group. George Allen \& Unwin, 268-274p.

QUEIROZ NETO, J. P. 1989. Vegetação fator de proteção do solo. Anais do $2^{\circ}$ Encontro Nacional de Estudos do Meio Ambiente. Universidade Federal de Santa Catarina. Florianópolis. 267277.

MATTECCI SILVA D., COLMA, A , 1982. Metodologia para el estudio de la vegetacion. Washington: Secretaria Geral de Organizacion de les estados Americanos, $168 p$.

MORGAN, R. P. C.; McINTYRE, K., VICKERES, A. W, QUINTON, J. N., RICKSON, R. J. 1997. A rainfall simulation study of soil erosion on rangeland in Swaziland. Soil Technogy, Amsterdam, 11:291-299.

MUELLER-DOMBOIS, D. \& ELLENBERG, H. 1974. Aims and Methods of Vegetation ecology. John Wiley \& Sons, New York, 120-140.

ORTIZ, L. F. 2000. Caracterização sócio-ambiental da bacia do córrego do Chiqueiro. Belo Horizonte: Instituto de Geociência da UFMG, 2000. 125p. (Dissertação de Mestrado)

RESENDE; CARVALHO FILHO \& LANI. 1990. Características do solo e da paisagem que influenciam a suceptibilidade à erosão. In: Simpósio sobre manejo e conservação do solo no cerrado, Goiânia, 33-67.

SOLÉ-BENET et al. 1997. Influences of micro-relief patters and plant cover on runoff related process in badlands from Tabernas (SE Spain). Elsevier Science B. V. Catena, 31:23-38.

STOCKING, M. 1985. Modelagem de Perdas de solo: Sugestões para uma aproximação brasileira Secretaria Nacional de produção Agropecuária e de Recursos Naturais, Brasília, 92p.

THORNES, J.B., 1990. Vegetation and Erosion: processes and environmes, John wilwy \& Sons, Chichester; New york, 1-5.

THORNES, J.B. 1985. The ecology of erosion, Geography, London, 2:222-235.

YOUNG, A. 1972. Slopes. Logman, Londres, 201-204p.

WILDNER, L. P. 1985. Efeito da adição de diferentes resíduos orgânicos nas perdas de solo e água em um solo podizólico vermelho amarela. Santa Maria, RS:UFMS,. 100p. dissertação (mestrado em Agronomia). 